\title{
The regional governance of climate adaptation: A framework for developing legitimate, effective, and resilient governance arrangements
}

Catrien Termeer, Art Dewulf, Helena van Rijswick, Arwin van Buuren, Dave Huitema, Sander Meijerink, Tim Rayner and Mark Wiering*

Abstract. Adaptation to climate change raises important governance issues. Notwithstanding the increasing attention on climate adaptation at the global and European level, the variety of local conditions and climate impacts points towards a prime role for regional actors in climate change adaptation. They face the challenge of developing and implementing adaptation options and increasing the adaptive capacity of regions so that expected or unexpected impacts of future climate change can be addressed. This paper presents a conceptual framework to analyse the regional governance of climate adaptation. It addresses the following key questions: (1) What are the distinct challenges for the regional governance of climate adaptation? (2) Which concepts can guide the design of new governance arrangements and strategies? (3) What challenges to legal principles are posed by the climate? (4) What research methods are suitable for developing and testing governance arrangements and strategies? We present a framework designed to address each of these questions; it has analytical, design, normative, and methodological components. In the paper, examples from the Dutch regional governance of climate adaptation serve as illustrations of the conceptual argumentation.

\section{INTRODUCTION}

There is increasing recognition of the need for society to adapt to the impacts of climate change, defined as "adjustment in natural or human systems in response to actual or expected climatic stimuli or their effects, which moderates harm or exploits beneficial opportunities". ${ }^{1}$ The flooding

* Catrien Termeer and Art Dewulf, Wageningen University; Helena van Rijswick, Utrecht University; Arwin van Buuren, Erasmus University Rotterdam; Dave Huitema, VU University Amsterdam; Sander Meijerink and Mark Wiering, Radboud University Nijmegen; Tim Rayner, University of East Anglia. The framework presented here was developed within the Governance of Climate Adaptation Consortium of the Dutch Knowledge for Climate Programme. It was financially supported by the Dutch Government and the Dutch "hotspot" areas. The authors are grateful for the comments made by the journal's anonymous referee.

${ }^{1}$ Climate Change 2007: Synthesis Report. Intergovernmental Panel on Climate Change, IPCC AR4 (2007). 
of New Orleans after Hurricane Katrina in 2005 demonstrated how vulnerable regions can be to large-scale disasters, even in wealthy parts of the world. Recent flooding in Pakistan (2010) and Brazil (2011) has demonstrated how much more devastating the damage can be for poorer countries. How, exactly, climate change will affect us is as yet unclear. Recent European assessments show a large degree of uncertainty about climate change damage projections for the coming century. Nevertheless, on the basis of these assessments, several conclusions may be drawn. ${ }^{2}$ First, climate change impacts, even with relatively small degrees of global warming, will impose significant new costs on European society. Second, there is great uncertainty about the scale of those costs. Under these circumstances, it is very difficult to determine an "optimal" adaptation strategy. Although adaptation will go some way towards reducing the expected costs, there will be unavoidable residual damage.

Adaptation to climate impacts involves both infrastructural adjustments, such as enhancing dikes or creating water-storage capacity, and broader processes of societal change, such as adjusting land-use planning, more efficient water use, or agricultural transitions. Because of the many uncertainties surrounding climate change issues, actors face the challenge not only of developing and implementing these adjustments and transitions, but also of increasing the adaptive capacity of society to be able to deal with unexpected future changes. ${ }^{3}$ A great deal of this adaptation will result from autonomous or planned actions of private actors. ${ }^{4}$ However, many aspects of adaptation have public-good characteristics, requiring collective action. Most people expect governments to safeguard them from the impacts of climate change; but are governments able and willing to guarantee this, and what do they expect from individual citizens and companies? And if it is clear what technical solutions or transition pathways need to be put in place, how might they be achieved?

In sum, adaptation to climate change is not only a complex technical issue, it is also a demanding matter of governance. Governance is here defined as the interactions between public and/or private entities ultimately aiming at the realization of collective goals. This broad definition comprises governing activities of governments, businesses, and civil-society actors; it encompasses economic, communicative, and regulatory steering mechanisms; and it embraces both structure and process. ${ }^{5}$

\footnotetext{
${ }^{2}$ Laurens M. Bouwer, Disasters and Climate Change: Analyses and Methods for Projecting Future Losses from Extreme Weather (2010).

${ }^{3}$ Dave Huitema, Jeroen Aerts, and Hendrik van Asselt, Adaptive Governance in Climate Change. The Cases of the International Climate Change Regime and Water Management the Netherlands, in Global Warming and Climate Change: Kyoto, Ten Years and Still Counting, 527 (V. Grover., ed., 2008); Andrew Jordan et al., Climate Change Policy in the European Union: Confronting the Dilemmas of Mitigation and Adaptation (2010).

${ }^{4}$ Nicholas Stern, Stern Review on the Economics of Climate Change (2006); Frans Berkhout, Julia Hertin, and D. M. Gann, Learning to Adapt: Organisational Adaptation to Climate Change Impacts, 78 Climatic Change 135 (2006).
}

${ }^{5}$ A. M. Kjaer, Governance (2004). 
In the academic realm, there has been a sizeable growth in the number of publications on the governance of adaptation to climate change. ${ }^{6}$ This literature has dealt with a plethora of topics, including, but not limited to, legal issues, innovative governance concepts (e.g. adaptive governance), assessment tools, adaptive policies and strategies, science-policy relations, and case studies of adaptation. ${ }^{7}$ However, many of these governance concepts and devices are rather abstract. ${ }^{8}$ Within governance systems, there is an urgent need to translate these theoretical concepts into practical governance arrangements. ${ }^{9}$ A governance arrangement is the ensemble of rules, processes, and instruments that structure the interactions between public and/or private entities to realize collective goals for a specific domain or issue. ${ }^{10}$ It mainly addresses the how to questions from a practical point of view.

Whereas climate mitigation puts the global and the national level centre stage, climate adaptation mostly focuses on local and regional responses. ${ }^{11}$ At the global level, mitigation-policy arrangements have been agreed upon under the Kyoto Protocol, including emission caps and emissions trading. Although these policies must be implemented across different levels, the location of the corresponding measures is irrelevant in reducing global emissions. Notwithstanding the increasing attention being paid to climate adaptation at the global and European level, the variety of local and regional conditions and climate impacts points towards a prime role for regional actors in climate change adaptation. ${ }^{12}$ Regional governance focuses on developing and realizing policies that minimize the potential damage at the regional level; that cope with the specific regional climate impacts; and that take advantage of opportunities for the regional actors. "Regional"

\footnotetext{
${ }^{6}$ See for an overview Antonius de Gier, Joyeeta Gupta and Helena F. M. W. van Rijswick, State of the Art on the Legal and Policy Literature on Adaptation to Climate Change: Towards a Research Agenda, Kennisvoor Klimaat, report number KfC001/09; Kim van Nieuwaal et al., A State of the Art of Governance Literature on Adaptation to Climate Change. Towards a Research Agenda (Paper presented at the Climate Change Conference: Global Risks, Challenges and Decisions, Copenhagen, Denmark, 10-12 March, 2009, Copenhagen).

${ }^{7}$ Neil Adger, Irene Lorenzoni, and K. O'Brien, K., eds., Adapting to Climate Change: Thresholds, Values and Governance (2009); Joseph Arvai et al., Adaptive Management of the Global Climate Problem: Bridging the Gap between Climate Research and Climate Policy, 78 Climatic Change 217 (2006); Ian Burton et al., Integrating Adaptation into Policy: Upscaling Evidence from Local to Global, 7 Climate Policy 371 (2007); Suraje Dessai and Mike Hulme, Assessing the Robustness of Adaptation Decisions to Climate Change Uncertainties: A Case Study on Water Resources Management in the East of England, 17 Global Env'l Change 59 (2007); E. Guba and Y. Lincoln, Fourth Generation Evaluation (1989); Carl Folke et al., Adaptive Governance of Social-Ecological Systems, 30 Ann. Rev. Env. Res. 441 (2005); Joyeeta Gupta et al., The Adaptive Capacity Wheel: A Method To Assess the Inherent Characteristics of Institutions to Enable the Adaptive Capacity of Society, 13 Env. Sci. Pol. 459 (2010); Per Olsson et al., Shooting the Rapids: Navigating Transitions to Adaptive Governance of Social-Ecological Systems, 11 Ecol. Soc. 18 (2006); Claudia Pahl-Wostl, The Importance of Social Learning in Restoring the Multifunctionality of Rivers and Floodplains, 11 Ecol. Soc. 10 (2006), online at http://www.ecologyandsociety.org/vol11/iss1/art10/; Bernd Siebenhüner, How Do Scientific Assessments Learn? Part 1. Conceptual Framework and Case Study of the IPCC, 5 Env. Sci. Pol. 411 (2002).

${ }^{8}$ Kim van Nieuwaal et al., supra note 6 .

${ }^{9}$ Interviews with key stakeholders in Dutch hotspots.

${ }^{10}$ Bas Arts and Pieter Leroy, Institutional Dynamics in Environmental Governance (2006).

${ }^{11}$ Neil Adger, Scales of Governance and Environmental Justice for Adaptation and Mitigation of Climate Change, 13 J. Int'l Dev. 921 (2001); Stern, supra note 4; Rob Swart et al., Europe Adapts to Climate Change: Comparing National Adaptation Strategies. Finnish Environment Institute (SYKE) No. 01/2009 (2009).

${ }^{12}$ Ibid.
} 
here refers to the subnational level and can vary from the level of neighbourhoods and villages up to the level of districts and provinces. Regional actors, such as municipalities, water boards, provinces, regional interest organizations, and housing cooperatives, play important roles in these regional governance structures. However, although much adaptation takes place at the regional level, this does not imply the exclusion of national and European actors. ${ }^{13}$ Indeed, the latter provide an important fiscal and regulative context for regional governance. For instance, a number of national governments in Western Europe have begun to develop comprehensive national adaptation strategies and policies to stimulate and coordinate adaptation. ${ }^{14}$

The focus on regional climate adaptation differs from country to country. The Netherlands, with its differentiated and high-value economic activities, its high population density, and most of its delta region lying below sea level, is exposed and sensitive to climate change impacts. The national government recently launched a "hotspots" approach to the problem. ${ }^{15}$ Hotspots are areas in the Netherlands that are especially vulnerable to climate change impacts, such as Schiphol Airport, the region of The Hague, the major rivers area, the city of Rotterdam, the peat-meadow areas, the dry rural areas, and the Wadden Sea. In these hotspots, governments, interest groups, businesses, and knowledge institutes develop and realize adaptation options and simultaneously reflect on the lessons learned. Through this hotspot policy, the Dutch government has deliberately opted for a regional approach to climate adaptation governance. This contrasts with some other national adaptation policies. Finland, for example, seeks to implement its national adaptation strategy in a sectoral way, by developing detailed operational adaptation plans by sector-for example, infrastructure, forestry, and tourism. ${ }^{16}$

On the basis of a review of the literature, this paper aims to present a conceptual framework for an analysis of the governance of climate adaptation, in order to enhance learning across regions, sectors, and countries. Special attention is paid to regional governance. This framework is not limited to evaluating existing governance strategies; rather, it deliberately aims to guide the design of governance arrangements that will contribute to developing and implementing adaptation options and increasing the adaptive capacity of society. We do so by addressing the following key questions: (1) What are the distinct challenges for the governance of climate adaptation and what are the dilemmas that it poses? (2) Which concepts can guide the development of new governance arrangements? (3) What challenges to legal principles are posed by climate adaptation? (4) What methods are best suited to develop and test these arrangements and enhance learning across regions and countries? To answer these questions, the literature has been examined both from climate-adaptation policy studies and from more general studies in the fields of public administration, governance, law, and planning. We use examples from the Dutch regional governance of climate adaptation to illustrate the conceptual argumentation.

\footnotetext{
${ }^{13}$ Elizabeth Wilson and Jake Piper, Spatial Planning and Climate Change (2010).

${ }^{14}$ Robbert Biesbroek et al., Europe Adapts to Climate Change: Comparing National Adaptation Strategies, 20 Global Env'l Change 440 (2010).

${ }^{15}$ Ibid.

${ }^{16}$ Ibid.
} 


\section{Specific Challenges and Dilemmas}

Climate change poses many complex questions and has therefore been called a "wicked problem par excellence". ${ }^{17}$ This has consequences for the governance questions that emerge in connection with climate change. ${ }^{18}$ The governance of adaptation will face all the usual difficulties, barriers, and opportunities in tackling difficult problems: changing political agendas, power-plays, conflicting interests and the need for lengthy negotiations, resistance from key groups, and windows of opportunity. On top of that, adaptation to climate change gives rise to some particularly demanding governance challenges and dilemmas. ${ }^{19}$ This section highlights three closely related challenges.

\section{A Context of Fragmentation}

Regional governance systems are nowadays notoriously complex, involving intricate relations between governmental, business, and civil-society actors, and they critically depend on national and supranational actors and institutions. ${ }^{20}$ The result is often a considerable fragmentation of actions among actors, sectors, and levels. Because climate change potentially impacts upon a variety of physical and social systems that are heavily interconnected, the governance systems that deal with the consequences of climate change are possibly even more fragmented than their counterparts in other policy domains. Climate adaptation affects domains which are as varied as water management, spatial planning, infrastructure, agriculture, forestry, energy supply, nature, health, and industry. These domains are all related to different policy sectors, administrative levels, and policy systems, which, in turn, are characterized by formal and informal rules, ambitions, problem-framing, and resources. Furthermore, climate change impacts provoke new interdependencies among these domains. For example, if a changing local climate pushes certain species to new territories, local spatial planning, regional water management, and national nature conservation policies may all be significantly affected. A confounding complexity is that climate vulnerabilities are often not easily separable from economic or social vulnerabilities, and therefore need to be linked to other such domains. ${ }^{21}$

Because of the many interdependencies between actors and problems, realizing successful adaptation strategies depends on the involvement and collaboration of many actors within and across

${ }^{17}$ Simin Davoudi, J. Crawford, and A. Mehmood, Planning for Climate Change: Strategies for Mitigation and Adaptation for Spatial Planners (2009); Andrew Jordan et al., supra note 3.

${ }^{18}$ Neil Adger et al., Governance for Sustainability: Towards a Thick Analysis of Environmental Decision-Making, 35 Environment and Planning A 1095 (2003); Andrew Jordan et al., supra note 3.

${ }^{19}$ Johannes Stripple et al., Governance Choices and Dilemmas in a Warmer Europe: What Does the Future Hold? in Andrew Jordan et al., supra note 3.

${ }^{20}$ S. Lister, Scales of Governance and Environmental Justice for Adaptation and Mitigation of Climate Change, 13 J. Int'1 Dev. 921 (2001); Geert Teisman, Arwin van Buuren, and Lasse Gerrits, eds., Managing Complex Governance Systems. Dynamics, Self-organization and Co-evolution in Public Investments (2009).

${ }^{21}$ Emma Tompkins and Neil Adger, Defining Response Capacity to Enhance Climate Change Policy, 8 Env. Sci. Pol. 562 (2005). 
these policy domains and levels. ${ }^{22}$ A dilemma arises when the involvement of an array of stakeholder networks is perceived as giving rise to opposition or delay. In response, more centralized and top-down forms of governance may appear attractive. In the Netherlands, this multi-actor, multi-sector, and multi-level context is often referred to in a negative sense, in terms of bureaucracy, administrative burdens, fragmentation, and conflicts over competencies and the division of roles.

For politicians and policymakers, it is hard to resist the temptation to advocate a radical reduction in complexity. For instance, there have been pleas for centralizing climate-adaptation policy through the establishment of a "climate director", a "climate watchdog", and a single "climate act". The key argument for this is that fragmented governance structures will never be able to provide the capacity required to tackle an issue which is as important as climate change. However, there are reasons to doubt that such a strategy_-representing a hierarchical or monocentric steering model - is feasible or desirable. As a result of the conceptual shift from "government" to "governance", 23 the idea that we must let go of the image of a malleable society steered by a central government has become dominant within public administration theory and practice. In the context of climate adaptation, the notion of multi-level governance is particularly relevant, as it involves interactions between various administrative levels. ${ }^{24}$ Furthermore, fragmented networks may be better able to provide the governance capacity to enable climate adaptation. ${ }^{25}$ Monocentric governance systems are deemed to be less capable of anticipating the unexpected and of creating space for variability and learning than a polycentric system - and that they therefore do not do justice to the fundamental uncertainties of the climate adaptation issue. ${ }^{26}$ Consequently, this multi-actor, multi-sector, and multi-level governance world forms the inescapable context for climate adaptation, because the ramifications of climate adaptation stretch across different policy domains and institutional levels.

\section{The Invention of a New Policy Domain}

The emergence of adaptation as a new domain of policy and practice is in itself an important challenge. Within this institutional void, adaptation is, for the moment at least, characterized by weakly defined ambitions, responsibilities, procedures, routines, and solutions. As a result, in developing the governance of adaptation to climate change, a series of basic governance

\footnotetext{
22 Joop Koppenjan and Erik-Hans Klijn, Managing Uncertainties in Networks: A Network Approach to Problem Solving and Decision Making (2004).

${ }^{23}$ Gerry Stoker, Governance as Theory: Five Propositions, 50 Int'1 Soc. Sci. J. 17 (1998); J. Pierre, ed., Debating Governance (2000).

${ }^{24}$ Liesbet Hooghe and Gary Marks, Unraveling the Central State, But How? Types of Multi-Level Governance, 97 Am. Pol. Sci. Rev. 233 (2003).

${ }^{25}$ Dave Huitema, Jeroen Aerts, and Hendrik van Asselt, supra note 3.

${ }^{26}$ Carl Folke et al., supra note 7; Sibout Nooteboom, Adaptive Networks: The Governance for Sustainable Development (2006); Brian Walker et al., Resilience Management in Socio-ecological Systems: A Working Hypothesis for a Participatory Approach, 6 Conserv. Ecol. 14 (2002); Karl Weick and Kathleen Sutcliffe, Managing the Unexpected: Assuring High Performance in an Age of Complexity (2001).
} 
dilemmas must be (re)addressed:. ${ }^{27}$ what problem should be addressed and how to frame it; at what levels should one act; how to act and with what instruments; when and in what order should one act; who wins and who loses; and how to deliver policy results? Such questions play a role in establishing the emerging policy domain of climate adaptation and can become the object of bureaucratic/political struggles about jurisdictions and budget allocations.

Calls for improved policy integration or "mainstreaming" raise the question of whether a separate policy domain of climate adaptation is necessary, or whether it is more effective to incorporate adaptation measures within existing policy domains and strategies. ${ }^{28}$ A related question is whether adaptation programmes are temporary or whether they have to be structurally anchored and embedded within public bureaucracies. There seem to be aspects of truth in both: specific adaptation policies are necessary, especially to correct the backlog built up in recent years (for example, in urban-retention capacity, river-discharge capacity, and freshwater supply), but much has also to be invested in climate-proofing existing policies with regard to mobility, transport, housing, and so on.

\section{Inherent Uncertainties in a Knowledge-Intensive Domain}

Decision making in relation to climate change is knowledge intensive. Without systematic observations and advanced mathematical models, even awareness of climate change would be very limited. At the same time, important uncertainties about the nature and scale of risks and the effectiveness of solutions will persist. ${ }^{29}$ In addition, controversy is inevitable when the many actors involved bring with them a variety of frames to make sense of a high-stake issue like climate change..$^{30}$ In spite of these inherent uncertainties and ambiguities, decisions about adaptation strategies need to be taken or prepared now.

Regional climate change knowledge has, because of its complexity and uncertainty, a particular feature: because data and models are mainly gathered and constructed at a global level, their translation to the level of affected regions implies a significant additional effort in which there is a risk of multiplying the uncertainties. This could lead to over-reaction or inadequate action being taken.

As noted above, the many actors involved bring with them a variety of perspectives or frames. These frames may differ in their overall conception of the causes of climate change, its seriousness and urgency, its risks and impacts at the geographical and political level concerned, and the burdens and benefits that may result. Different perspectives also exist concerning the normative

\footnotetext{
${ }^{27}$ Constanze Haug et al., Navigating the Dilemmas of Climate Policy in Europe: Evidence from Policy Evaluation Studies, 101 Climatic Change 427 (2009).

${ }^{28}$ M. Kok and H. C. de Coninck, Widening the Scope of Policies to Address Climate Change: Directions for Mainstreaming, 10 Env. Sci. Pol. 587 (2007).

${ }^{29}$ Joseph Arvai et al., supra note 7.

${ }^{30}$ Mike Hulme, Why We Disagree about Climate Change: Understanding Controversy, Inaction and Opportunity (2009).
} 
and political questions of how to legitimately pool or allocate the above risks, burdens, and benefits. The conflicting frames were thrown into particularly sharp relief in recent international climate-science controversies; they affected national climate debates and potentially complicated regional climate policies. ${ }^{31}$ In the so-called "Climategate" controversy, ${ }^{32}$ we witnessed how both traditional and new media play an important role in giving voice to climate change sceptics, creating the particularly challenging situation for climate adaptation policy whereby the very existence of climate change or of human influence on the climate are called into question. These global debates have heavily influenced the legitimacy of climate-adaptation policies at the local level.

Clearly, both the uncertainties and the ambiguities ascribed to the climate change issue affect the perceived legitimacy of climate science and climate adaptation policy in particularly challenging ways. First, it is necessary to anticipate (highly) uncertain future developments, therefore involving inherently difficult policy decisions ${ }^{33}$ Second, strong pressures exist to give priority to economic interests in the short term. To combine long-term ambitions with short-term urgency is a serious challenge. A further complication is the different time scales of physical, economic, and political processes, which are difficult to align. And finally, short-term interventions based on a long-term vision demand a specific and durable commitment by taxpayers, politicians, or citizens.

\section{Key ConcePts for Developing Governance ArRangements}

In this part we outline three key concepts as possible responses to the governance challenges posed by climate adaptation which could guide research on governance arrangements for climate adaptation: (1) organizing connectivity, (2) (re)allocating responsibilities, and (3) dealing with controversies.

\section{Organizing Connectivity}

As mentioned above, the governance systems which have to deal with the consequences of climate change are highly fragmented. The concept of organizing connectivity addresses this challenge. Connectivity refers to bringing actors, issues, sectors, and scale levels together to realize creative climate-adaptation options that do justice to different values, interests, and motives. This is necessary in order to deal both legitimately and effectively with the consequences of climate change. The question is how to realize connectivity within a highly fragmented governance system. We propose four sets of strategies which may be used to organize "connectivity for adaptation". They have to do with connecting policy domains, scale levels, the old and the new, and leadership.

\footnotetext{
${ }^{31}$ Frans Berkhout, Reconstructing Boundaries and Reason in the Climate Debate, 20 Global Envir Chang, 565 (2010); B. Nerlich, 'Climategate': Paradoxical Metaphors and Political Paralysis, 19 Env'l Values 419 (2010).

${ }^{32}$ Ibid.

${ }^{33}$ Nicholas Stern, supra note 4.
} 


\section{A. Connecting Policy Domains}

A first set of strategies aims at synchronizing policy processes in various domains to enable creative solutions for multiple land-use strategies. The realization of many climate adaptation strategies will lead to land-use claims, which can be accommodated more easily if they are integrated with existing land use or linked to other land-use claims. For instance, the development of special areas for water retention in the city of Rotterdam is more easily achieved when those areas are designed as multi-functional city squares that creatively integrate water retention strategies with landscaping and more recreational facilities. Another example is the construction of a 100-metre-wide Delta Dike near the Wadden Sea, which has a much higher resistance to breakthrough than normal dikes. ${ }^{34}$ Its width makes it possible to use the area on top of the dike for the development of housing, nature, and recreational amenities, as well as transportation routes. However, despite the innovative thinking involved, neither project has yet been realized. There are many barriers to the implementation of multi-functional land-use plans within pillared and fragmented governance systems. Generally, each policy domain or governance pillar is characterized by different assumptions, aims, procedures, and networks. Negotiation across policy domains is often a laborious process. Innovative solutions are often difficult to align with existing laws and procedures. Regional innovations have to cope not only with regional rules (those of the municipalities and provinces) but also with those at the national and European level. For example, water retention in city squares conflicts with safety standards (children could drown in reservoirs). Mainstreaming climate adaptation into existing policy domains regarding infrastructure, housing, nature conservation, and agriculture calls for new boundary arrangements fostering system synchronization. ${ }^{35}$ Examples of boundary arrangements vary from the appointment of liaison officers or climate-adaptation ambassadors to integrated licences or procedures that synchronize different decision-making processes.

\section{B. Connecting Scale Levels}

The second set of strategies takes as its starting point the multi-level character of governance systems in the field of adaptation. Various regions attempt to formulate adaptation strategies for which they are highly dependent on both national policy ambitions and local planning processes and their evolution. The crucial challenge is how to establish effective and legitimate governance arrangements that align national, regional, and local planning, and investment processes, in order to safeguard long-term climate robustness. ${ }^{36}$ Here, lessons can be learned from network

\footnotetext{
${ }^{34}$ Pier Vellinga, N. A. Marinova, and Jantsje van Loon-Steensma, Climate-Proofing the Flood Protection of the Netherlands, 88 Geologie en Mijnbouw 3 (2009).

${ }^{35}$ Geert Teisman, Arwin van Buuren, and Lasse Gerrits, supra note 20.

${ }^{36}$ Arwin van Buuren, Jean-Marie, Buijs, and Geert Teisman, Program Management and the Creative Art of Competition. Dealing with Potential Tensions and Synergies between Projects of Spatial Development, 28 Int'1 J. Proj. Management 672 (2010).
} 
management, multi-party collaboration, meta-governance, and partnerships. ${ }^{37}$ These theories provide amongst other things guidelines for the design and managements of multi-actor processes, such as organizing a sense of urgency, preventing deadlocks, appointing an independent process manager, or minimizing transaction costs. ${ }^{38}$ The Dutch "Space for the River" project provides an example of an effective multi-level governance arrangement design in the Great Rivers region. ${ }^{39}$ The central objectives were to develop and implement river-widening measures, which improved both the safety of inhabitants and the spatial quality of the riverine areas. The three relevant ministries decided to involve regional and local government agencies, NGOs, and the affected inhabitants. Within the context of a number of strict conditions (concerning financing, discharge rates, and time lines), the national government asked the regional authorities to issue regional advice on a package of policy measures that met the objectives set by the national government and that could be combined with other (more local and regional) policy objectives. Through an advanced decision-support system, the local and regional parties involved could learn about the impact that various combinations of policy measures would have on the water levels in the main rivers. Administrative contracts were introduced that made local and regional government agencies responsible for a specific river-widening measure. In this way, governance arrangements were introduced that combined centralized and decentralized steering as well as organized interfaces between scales and levels; they also supported the joint learning process of the parties involved.

\section{Connecting the Old and the New}

The third set of strategies to organize connectivity is experimentation. Within the highly fragmented structure of modern governance systems, connections across boundaries do not develop automatically; institutional lock-ins still set the tone. ${ }^{40}$ Therefore experiments or pilot projects are necessary to realize new linkages. ${ }^{41}$ In line with current insights from the literature on integrated assessment, policy evaluation, and science, an experimenting society involves its experts,

\footnotetext{
${ }^{37}$ Walter Kickert, Erik-Hans Klijn, and Joop Koppenjan, Managing Complex Networks: Strategies for the Public Sector (1997); David Greenberg, Donna Linksz, and Marvin Mandell, Social Experimentation and Public Policymaking (2003); Maarten Hajer and Hendrik Wagenaar, Deliberative Policy Analysis: Understanding Governance in the Network Society (2003); Frank Fischer, Reframing Public Policy: Discursive Politics and Deliberative Practices (2003); Martha Feldman and Anne Khademian, The Role of the Public Manager in Inclusion: Creating Communities of Participation, 20 Governance 305 (2007); John Diamond and Joyce Liddle, What Are We Learning From the Partnership Experience? 20 Public Policy Admin. 1 (2005); Chris Huxham and Siv Vangen, Leadership in the Shaping and Implementation of Collaboration Aagendas, 43 Acad. Management J. 1159 (2000); Ellen Van Bueren, Erik-Hans Klijn, and Joop Koppenjan, Dealing with Wicked Problems in Networks: Analyzing an Environmental Debate from a Network Perspective, 13 J. Public Admin. Research Theory 193 (2003).

${ }^{38}$ Joop Koppenjan and Erik-Hans Klijn, supra note 22.

${ }^{39}$ Ernst ten Heuvelhof et al., Procesevaluatie totstandkoming PKB Ruimte voor de Rivier, The Netherlands, Berenschot (2007).

${ }^{40}$ Dave Huitema, Jeroen Aerts, and Hendrik van Asselt, supra note 3.

${ }^{41}$ Carl Walters, Challenges in Adaptive Management of Riparian and Coastal Ecosystems, 1 Conserv. Ecol. 1 (1997), online at http://www.ecologyandsociety.org/vol1/iss2/art1/; Claudia Pahl-Wostl, supra note 7.
} 
stakeholders, ordinary citizens, and policymakers in a process of collective discovery. ${ }^{42} \mathrm{We}$ are quite far removed from the ideal of an experimenting society, not least in the domain of governmental policymaking. Experimentation is difficult to initiate for ethical reasons (treating one group of citizens differently from another), and because the results of experiments are not always easy to measure and do not always allow for clear choices. ${ }^{43}$ This is why most experiments in governance settings are in reality "quasi-experiments", meaning that they are more about organizing "institutional space" for innovation and creativity than about testing hypotheses with control groups. For instance, The Hague Hotspot has initiated so-called "field experiments" in which different ways of integrating climate adaptation with other challenges (such as the restructuring of housing districts, greenhouse areas, and industrial parks) are developed and tested. In these spaces, established policy objectives may be questioned, modified, or even abandoned, and alternative strategies can be tested and implemented. ${ }^{44}$ Furthermore, experimentation can be an effective way of loosening up policy systems, as shown in international comparative work on water management. ${ }^{45}$

\section{Connecting Leadership}

A final set of strategies are the leadership strategies of individual people to realize connections within fragmented governance systems. Both government officials and elected politicians involved in practices of climate adaptation face the challenge of enhancing coordination and cooperation across different levels, sectors, and actors. The Dutch government has appointed a national climate director and seven regional directors. Their task is to organize networks, to facilitate discussions, and generally to develop fertile ground so that, with time, important climate-adaptation decisions can be taken and implemented. The concepts of catalytic leadership, ${ }^{46}$ collaborative leadership, ${ }^{47}$ connective leadership ${ }^{48}$ and integrative leadership ${ }^{49}$ are all relevant here. These leadership concepts point to the need for joint problem-solving, the development of multiple policy options, and building trust and legitimacy within multi-level governance networks. The same could be said about new leadership concepts like complex-

\footnotetext{
${ }^{42}$ E. Guba and Y. Lincoln, supra note 7; Frank Fischer, Evaluating Public Policy (1995); Roger Pielke, The Honest Broker: Making Sense of Science in Policy and Politics (2007).

${ }^{43}$ Ian Sanderson, Evaluation, Policy Learning and Evidence-based Policy Making, 80 Pub. Admin. 1 (2002).

${ }^{44}$ Frank Fischer, supra note 42; David Greenberg, Donna Linksz, and Marvin Mandell, supra note 37.

${ }^{45}$ Dave Huitema and Sander Meijerink, eds., Water Policy Entrepreneurs: A Research Companion to Water Transitions around the Globe (2009).

${ }^{46}$ Jeffrey Luke, Catalytic Leadership, Strategies for an Interconnected World (1998).

${ }^{47}$ David Chrislip, The Collaborative Leadership Fieldbook: A Guide for Citizens and Civic Leaders (2002).

48 Jean Lipman-Blumen, Connective Leadership: Managing in a Changing World (1996).

${ }^{49}$ B. C. Crosby and J. M. Bryson, Integrative Leadership and the Creation and Maintenance of Cross-Sector Collaborations, 21 Leadership Q. 211 (2010).
} 
ity leadership, ${ }^{50}$ eco-leadership, ${ }^{51}$ policy entrepreneurship in transition processes,${ }^{52}$ and the building of shadow networks. ${ }^{53}$ These concepts inform us about strategies that may be used to deal with the uncertainties surrounding climate change and to increase the adaptability of the governance system. The question remains, however, as to which combinations of leadership strategies are most appropriate to influence the policy process to get adaptation policies accepted and realized and how leaders can make sense of these abstract strategies in day-to-day governance practices.

\section{2. (Re)allocating Responsibilities and Costs and Benefits}

In contrast to organizing connectivity, this guiding concept aims at changing the existing fragmented governance structures by rearranging the allocation of responsibilities and costs and benefits among a variety of actors. We propose two broad directions. The first concerns the reallocation of responsibilities to public and/or private organizations, and the second concerns a reallocation of costs and benefits through the introduction of economic instruments, especially so-called climate services.

\section{A. (Re)allocating Responsibilities}

Above we mentioned that climate adaptation has public-good characteristics and therefore requires collective action and involves governmental responsibilities. In the global context, the question of the allocation of responsibilities for funding climate adaptation is heavily debated, especially in the context of North-South relations. Yet, in many regional governance practices, this question is hardly addressed. The city of Rotterdam provides some examples. The "Green Roofs" project has been selected as an effective measure to diminish both heat stress and $\mathrm{CO}_{2}$ emissions. However, the municipality has yet to decide on who will construct and pay for these roofs. The city is also involved in debates about responsibility for flood damage to houses in unembanked areas, built in the nineteenth century or earlier. Another problem highlights the "control paradox". Flood prevention measures encourage more intensive land use behind the dikes (because people feel safer). It follows that, when disastrous flooding occurs, there will be a greater extent of damage and more people will experience a strong feeling of being at risk. This provides an impetus to raise and strengthen the dikes once again. ${ }^{54}$ Moreover, people who feel

\footnotetext{
${ }^{50}$ Mary Uhl-Bien, R. Marion, and Bill McKelvey, Complexity Leadership Theory; Shifting Leadership from the Industrial Age to the Knowledge Era, 18 Leadership Q. 298 (2007).

${ }^{51}$ Richard Wielkiewicz and Stephen Stelzner, An Ecological Perspective on Leadership Theory, Research and Practice, in Leadership for Environmental Sustainability, 17-35 (B. W. Redekop, ed., 2010).

52 B. C. Crosby and J. M. Bryson. Leadership for the Common Good: Tackling Public Problems in a SharedPower World (2005); Sander Meijerink and Dave Huitema, Policy Entrepreneurs and Change Strategies: Lessons from Sixteen Case Studies of Water Transitions around the Globe, 15 Ecol. Soc. 21 (2010), online at http://www.ecologyandsociety.org/vol15/iss2/art21/.

${ }^{53}$ Per Olsson et al., supra note 7.

${ }^{54}$ Mark Wiering and I. Immink, When Water Management Meets Spatial Planning: A Policy-Arrangements Perspective, 24 Environment and Planning C 423 (2006).
} 
safe behind the dikes, and trust that the government will take care of them, will not develop the preparedness or the learning capacity needed for times of crisis. ${ }^{55}$ This moral-hazard dilemma challenges the development of arrangements in which private parties are encouraged to play a role in developing adaptation strategies.

\section{B. (Re)allocating Costs and Benefits}

The second direction aims at developing new economic instruments for allocating costs and benefits and creating new systems of economic incentives. The main instruments considered include traditional instruments like taxes ${ }^{56}$ but also more innovative ones such as the creation and implementation of water markets ${ }^{57}$ or climate services. ${ }^{58}$ In many Dutch regions, climate services are one of the most promising concepts. In general, "climate service" may be defined as an investment that is delivered by a private actor and increases adaptive capacity. The Hague region, for example, suffers from water abundance during times of heavy rainfall. Due to the high building density, less room is left for temporary water storage. A solution was found in greenhouse farmers who could provide water storage as a service, by investing in underground water-storage tanks. Everyone in the neighbourhood can benefit from this investment because water storage offered by others reduces the risk of one's land, roads, and even houses being flooded. The design of such climate-service arrangements, and especially its payment schedules, have to deal with two challenges. First, the stakeholders in climate adaptation policies cannot easily be separated into suppliers and consumers of climate services. On the one hand, most of the stakeholders involved are able to provide climate services (at different costs and in different quantities), yet, on the other hand, they are tempted to free-ride on the services provided by others. The second reason why designing climate-service arrangements is difficult is that the regulatory authorities usually have less information about the benefits and costs of climate-service projects than the stakeholders involved. Hence regulation takes place under conditions of asymmetric information.

\section{Dealing With Controversies}

The final guiding concept is about developing arrangements to deal with the inherent climaterelated uncertainties, stakeholders' frames of reference, and contested knowledge. The challenge is to take these differences into account without paralyzing decision-making processes. It requires knowledge of methods of dialogue, learning, negotiation, and co-production of knowledge. We distinguish two directions.

\footnotetext{
55 Joyeeta Gupta et al., supra note 7.

${ }^{56}$ William Jack Baumol and W. E. Oates, The Theory of Environmental Policy (2 ed.,1988).

57 T. D. Crocker, The Structuring of Atmospheric Pollution Control Systems, in The Economics of Air Pollution, 61-86 (H. Wolozin, ed., 1966).

58 John Rolfe, Jill Windle, and J. McCosker, Testing and Implementing the Use of Multiple Bidding Rounds in Conservation Auctions: A Case Study Application, 57 Can. Ag. Econ. 287 (2009).
} 


\section{A. Dealing with Frame Conflicts}

The first direction aims at developing arrangements for dealing with different frames of reference in decision-making processes. The starting point is the analysis of the diversity of the different governmental and societal stakeholders involved in the climate change discussion, and the frames they employ to make sense of the adaptation issue. Theories like collaborative governance, ${ }^{59}$ network governance ${ }^{60}$ or reflexive governance ${ }^{61}$ provide strategies to find workable ways to take multiple frames into account. Between the extremes of rational problem solving (assuming that frame differences are non-existent or easily reconcilable) and oppositional modes of action (where the clash of ideas becomes a clash between people), three broad modes of action may be distinguished:62 (1) attracting others into a particular frame, (2) connecting the different frames, or (3) negotiating a deal despite the frame differences.

The first mode assumes that a convincing account can dissolve differences by persuading people of the meaningfulness of one particular frame of reference, thus creating common ground for action. ${ }^{63}$ The second mode assumes that the different frames need to be somehow connected in the way the situation is addressed. The connection could take different forms, including integrating existing frames through a creative synthesis, adding a new superordinate frame that overarches the variety of existing frames, bridging different frames at points where they overlap, or collectively redesigning the situation so that the differences in the frames are accounted for. ${ }^{64}$ The third mode assumes that the different frames are there to stay and that connecting them is neither feasible nor desirable. The goal is to find a mutually beneficial deal that is meaningful from multiple perspectives, ${ }^{65}$ albeit potentially for very different reasons. This requires skilful negotiations in which the various frames are explored but not questioned.

\section{B. Dealing with Contested Knowledge}

The second direction focuses on the development of legitimate scientific knowledge. Scientific knowledge concerning climate change is often available at global and national levels, whereas its societal acceptance and its political relevance largely plays out at, and depends on, regional

\footnotetext{
${ }^{59}$ Barbara Gray, Collaborating. Finding Common Ground for Multiparty Problems (1989); Chris Huxham, The Challenge of Collaborative Governance, 2 Public Management Rev. 337 (2000).

${ }^{60}$ Erik-Hans Klijn and Joop Koppenjan, Public Management and Policy Networks: Foundations of a Network Approach to Governance, 2 Public Management Rev. 135 (2000).

${ }^{61}$ Carolyn Hendriks and John Grin, Contextualizing Reflexive Governance: The Politics of Dutch Transitions to Sustainability, 9 J Env. Pol. Plan. 333 (2007).

${ }^{62}$ Marcela Brugnach et al., More Is Not Always Better: Coping with Ambiguity in Natural Resources Management, J. Env. Management 92(1), 78-84 (2011).

${ }^{63}$ Robert Benford and David Snow, Framing Processes and Social Movements: An Overview and Assessment, 26 Ann. Rev. Sociol. 611 (2000).

${ }^{64}$ Donald Schön and Martin Rein, Frame Reflection: Toward a Resolution of Intractable Policy Controversies (1994).

${ }^{65}$ Lawrence Susskind and Elaine Landry, Implementing a Mutual Gains Approach to Collective Bargaining, 7 Negotiation J. 5 (1991).
} 
or local levels. As indicated earlier, by downscaling the geographical level of information, thus downscaling variables, processes, and impacts from global, continental, or national modelling efforts, one tends to multiply the scientific uncertainties. Regional actors will have to pay attention to the way "scientific knowledge" is produced, used, downscaled, valued, and evaluated by the public. At the national level in the Netherlands, there is a more or less established pattern of science-policy interface, for example through environmental and economic forecasts by the Netherlands Environmental Assessment Agency. These reports are underpinned by data and insights from a broad array of other scientific institutions, embedded in a multi-actor arrangement including advisory boards. At the regional or hotspot level, though, there is hardly any such established science-policy arrangement. This raises questions about the actual handling of the regional transfer and translation of data formatted and modelled at higher levels, and it raises questions about the quality control of the information used. As may be clear from the above, this quality control should cover not only scientific quality, including how one deals with uncertainties, but also its societal robustness. ${ }^{66}$

\section{Rethinking Legal and Policy Principles}

Adaptation to climate change and related governance responses call into question many normative principles currently underlying policymaking and implementation. ${ }^{67}$ We can find examples of shifting normative principles in practically every policy domain relating to the governance of climate adaptation, yet these shifts are not usually made explicit. ${ }^{68}$ Should established legal and policy principles in the public domain remain the same, or can they be maintained in the face of climate change, and — if not— to what extent do they need to be reconsidered?

First, the role of specific principles depends on the public interest at stake. In general, governmental action has to be in the public interest to justify state regulation and policy intervention. It is therefore important to clarify and structure the debates on what the government undertakes in the public interest, who defines what the public interest is, and what legal and policy principles these actions are based upon. It has also been argued that adaptation to climate change, especially in the field of US water law, should be reframed as a public necessity; moreover, it should be reframed as an emergency response and preparedness. This is necessary because the United States will suffer from increasingly serious droughts, and the available amount of fresh water is seriously diminishing. However, this more radical approach is a consequence of the legal system in the United States, which is based on water-property rights — called the "property rights barrier" by Robin Kundis Craig. This situation, however, is the opposite to the one in the Netherlands, where water is a public good whose use has been regulated in the field of administrative law,

\footnotetext{
${ }^{66}$ Michael Gibbons et al., The New Production of Knowledge. The Dynamics of Science and Research in Contemporary Societies (1994); Helen Nowotny, Peter Scott, and Michael Gibbons, Re-thinking Science: Knowledge and the Public in an Age of Uncertainty (2001).

${ }^{67}$ Rosalind Cook and Eljalill Tauschinsky, Accommodating Human Values in the Climate Regime, 4 Utrecht Law Review 18 (2008).

${ }^{68}$ Antonius de Gier, Joyeeta Gupta, and Helena F. M. W. van Rijswick, supra note 6.
} 
with a strong legal focus on a fair distribution of scarce water among all users, with a view to protecting, in the public interest, the amount of scarce fresh water. ${ }^{69}$

In the field of adaptation to climate change, several interests may be distinguished. Flood protection is indisputably one of the oldest public interests with which Dutch governments have had to concern themselves. Without protection against flooding, little would remain of the Netherlands. Currently, flood protection — at least in the Netherlands - could be characterized as being based on a unitary and dialogical concept of public interest. ${ }^{70}$ For a long time, flood defences have been a public task for regional authorities, more specifically for the typical Dutch water boards. Measures taken in this public interest are based on a combination of the solidarity principle and the profit principle, as well as shared responsibility. ${ }^{71}$ However, the way protection against flooding is realized is changing. The Netherlands is moving from building the traditionally strong dikes towards a more integrated approach that combines flood protection with improving regional spatial quality, enabling economic development, and restoring the natural environment. With this development, more regional authorities, such as provinces and municipalities, and more stakeholders will be involved. These authorities have other ways of defining the public interest and there is hardly any relation between those who profit from adaptation measures and those who pay for these measures. Shared responsibilities as adopted in recent Dutch water legislation and as also suggested for the European level ${ }^{72}$ may tackle problems that arise with the shifts in governance due to adaptation strategies, but we must also consider that the idea that the government will take care of the safety of all who live behind the dikes may change, at least for some groups of the population. As mentioned before, this will lead to a shift towards citizens having to take more responsibility, and, furthermore, a differentiation in protection levels for different groups will lead to discussions on equal treatment and human values.

Second, a whole range of principles used in climate-related policy fields, including equitable justice, ${ }^{73}$ the user-pays or polluter-pays principle (and the related cost-recovery principle), the non-shift principle, the precautionary principle, the right to be compensated when one suffers

\footnotetext{
${ }^{69}$ Robin Kundis Craig, Adapting Water Law to Public Necessity: Reframing Climate Change Adaptation as Emergency Response and Preparedness, 11 Vermont J. Env. Law 709 (2010).

${ }^{70}$ Ernest Alexander, The Public Interest in Planning: From Legitimation to Substantive Plan Evaluation, 1 Plan. Theory 226 (2002).

${ }^{71}$ In the United States, the Public Trust Doctrine tries to combine public interest with the traditional private rights approach: Robin Kundis Craig, A Comparative Guide to the Western States' Public Trust Doctrine: Public Values, Private Rights, and the Evolution Toward an Environmental Public Trust (2009) available at http//works.bepress.com/robin_craig/5; Ernest Alexander, supra note 71.

${ }^{72}$ The Water Act; see also Helena F. M. W. van Rijswick, Herman Kasper Gilissen and Jasper J. H. van Kempen, The Need for International and Regional Transboundary Cooperation in European River Basin Management as a Result of New Approaches in EC Water Law, 11 ERA (Europaische Rechts Akademie) Forum 129 (2010).

${ }^{73}$ See Dinah Shelton, Equity, in The Oxford Handbook of International Environmental Law, 639-62 (Daniel Bodansky, Jutta Brunnée, and Ellen Hey, eds., 2007); Rosalind Cook, Legal Responses for Adaptation to Climate Change. The Role of the Principle of Equity and Common but Differentiated Responsibility (2010) available at www.milieurecht.nl.
} 
more than others due to governmental measures (égalité devant les charges publiques), ${ }^{74}$ and the proportionality and subsidiarity principles, are being questioned. For instance, there is no straightforward answer to the question of who should bear the burden of climate adaptation. ${ }^{75}$ On the basis of the polluter-pays principle, one might want to target the producers of greenhouse gases, but difficulties with linking particular emissions to climate change and its effects make this highly problematic. In light of the user-pays principle and the obligatory recovery of costs for water services, it may be argued that those who are not paying for the use of fresh water should do so in the future. However, agriculture interest groups argue that they have a right to free fresh water. The non-shift principle leads to discussions on whether the burden of adaptation can be shifted to future generations, or to those living downstream or upstream of the river, and so on. A solution for legitimate governance adaptation to climate change requires a clear analysis of the public interests that are at stake and an analysis of the role and priority of the leading principles in the decision-making process. It is not necessary for each adaptation measure by each authority to be based on the same principles and the same ranking of public interests, but to improve the legitimacy of adaptation measures it is important that all stakeholders are informed and can understand the more fundamental choices that have been made before practical measures are undertaken. ${ }^{76}$ Finally, legitimate and effective conflict mechanisms are necessary to avoid problems that normally go hand-in-hand with transitions. ${ }^{77}$

Third, adaptation may require new legal arrangements that provide more room for adaptive capacity. ${ }^{78}$ For instance, it has been argued that adaptation to climate change leads to a greater need for flexibility in legal regimes, but that this should be combined with traditional legal values. ${ }^{79}$ Existing instruments that have resulted from the European Water Framework Directive and implemented in the law of the member states — such as regular planning cycles, the obligatory revision of plans and measures relating to monitoring results, legal exemptions that are relevant when one has to deal with the uncertainties that are typical of climate change, and monitoring obligations that provide an opportunity for experiments and shared responsibilities_may be of

\footnotetext{
${ }^{74}$ Herman Kasper Gilissen, The Influence of Liability Law on Adaptation to Climate Change, Paper presented at the Conference on Law for Social-Ecological Resilience, 17-19 November 2010, Stockholm see www.juridicum.su.se/resilience.

${ }^{75}$ Daniel Farber, Adapting to Climate Change: Who Should Pay? Public Law Research Paper No. 980361, School of Law, University of California at Berkeley (2007).

${ }^{76}$ Partly overlapping with the five principles for climate change adaptation law: Robin Kundis Craig, Stationary is Dead, Long Live Transformation: Five Principles for Climate Change Adaptation Law (2009) From the selected works of Robin K. Craig, March 2009, available at http//works.bepress.com/robin_craig/4.

${ }^{77}$ Barbara Cosens, Resolving Conflict in Non-Ideal Complex Systems: Solutions for the Break-Down in Environmental and Natural Resource Law, 48 Nat. Res. J. 1 (2008).

${ }^{78}$ Helena F. M. W. van Rijswick et al., Towards Resilience in Water Law and Water Management, The Governance of Adaptation to Climate Change. Paper presented at the Conference Law for Social-Ecological Resilience, 17-19 November 2010, Stockholm see www.juridicum.su.se/resilience.

${ }^{79}$ Jonas J. Ebbesson, The Rule of Law in the Governance of Complex Socio-ecological Changes, 20 Global Env. Change 414 (2010); Jutta Brunnée and Stephen Toope, Legitimacy and Legality in International Law; An Interactional Account (2010); Helena F. M. W. van Rijswick, Moving Water and the Law; On the Distribution of Water Rights and Water Duties within River Basins in European and Dutch Water Law (2008).
} 
special importance for adaptation to climate change as they improve the resilience of a legal system, while they still respect traditional legal values such as legal certainty. The binding European legislation in the field of water management, nature protection, public participation, and access to justice stands as a further challenge to this idea. Whereas the traditional Dutch decentralized approach may work well and be followed by way of more European attention being paid to regional governance, European law may at the same time lead to greater centralization, because member states have to ensure that regional and local authorities correctly implement European obligations.

A relevant example is the case of the Haringvliet Locks in the southwest delta of the Netherlands. The locks were built as part of the Delta Works. The Delta Works were carried out after the severe flooding in 1953 to protect the Netherlands against flooding and rises in sea level. The Delta Works consist of - among other things-dams, locks, and other water works that almost completely close off the delta's estuary from the sea. Because these works have severe negative impacts on the ecological system upstream in the Rhine, Meuse, and Scheldt rivers, the national government decided to open the Haringvliet Locks for set time periods during the day. This measure is part of the international river-basin management plan for the Rhine and Meuse rivers. Restoring the tide in the estuary will improve the ecology of the rivers. Fish migration from the sea towards the rivers will be possible once again. The Rhine and Meuse river states have already made many investments and taken measures upstream to improve ecological quality and fish migration, and these investments will be useless if the estuary remains closed for fish migration due to the dams and locks that have been built by the Dutch government. The upstream states have urged the Netherlands to take responsibility for the ecological improvement of the transboundary river basins. Opening the Haringvliet Locks is therefore an important obligation which follows from the European Water Framework Directive. However, this decision has been contested by the Dutch government because of strong protests by regional authorities and regional stakeholders, who fear a loss of fresh water for drinking and agriculture. Although ecological protection and improvement is regarded as being in the public interest, the way this interest is defined is quite different compared to the interest of safety against flooding or the supply of drinking water. In addition to safety arguments, agricultural-interest organizations have argued that they have a right to use fresh water for free and that this right would be breached by opening the locks because then the water would become more saline. The question was raised as to how far existing freshwater rights should be protected for the sake of the principle of legal certainty. Because of strong regional protests, the Dutch government decided to rescind the decision to open the locks. Currently, the other river basin states are accusing the Netherlands of shifting the burden and not complying with European laws. ${ }^{80}$

${ }^{80}$ Andrea M. Keessen, J. J. H. van Kempen, and Helena F. M. W. van Rijswick, Transboundary River Basin Management in Europe; Legal Instruments to Comply with European Water Management Obligations in Case of Transboundary Water Pollution and Floods, 4 Utrecht Law Review 35 (2010); Helena F. M. W. van Rijswick, Herman Kasper Gilissen and J. J. H. van Kempen, supra note 73. 


\section{Towards Usable Knowledge About the Governance of Adaptation}

Adaptation policies are still in their infancy. Although the first set of reports by the Intergovernmental Panel on Climate Change did indeed include a report on impacts and adaptation measures, the emphasis was on mitigation. ${ }^{81}$ It is only in the post-2000 period that there has been a gradual emergence of the adaptation challenge on the political agenda. ${ }^{82}$ For instance, Finland, which was the first European country to issue a National Adaptation Strategy, did so in 2004 The Netherlands only published its National Strategy in $2007^{83}$ and launched its regional hotspot approach in 2010. Governments are still thinking about what they have to do and how they have to do it. In many Dutch hotspots, for example, processes between public, civic, and private actors regarding climate adaptation have just started. On the one hand, this can be seen as a serious impediment to carrying out empirical research on the effectiveness and legitimacy of regional climate adaptation, but at the same time-and more importantly - it is a welcome challenge to intertwine the development of governance arrangements in practice with reliable knowledge about the governance of adaptation.

Therefore we believe that collaborative action research methods can be very useful. ${ }^{84}$ Very briefly, collaborative action research means that the researchers take guidance from the regional actors as the primary source of questions, dilemmas, and empirical data, but also collaborate with them in testing insights and strategies, and evaluating their usefulness. A key characteristic of collaborative action research is the continuous feedback loop between analytical activities (theory building, formulating hypotheses) and empirical activities (interventions, observations). ${ }^{85}$ Close interaction between scientists and practitioners improves not only the utilization of scientific knowledge, but also its quality in terms of its sensitivity to contextual factors, the incorporation of local knowledge, and its relevance. Action research presupposes a willingness to learn and reflect on the part of the practitioners, and an ability to be flexible and responsive on the part of the scientists. Collaborative action research is not only a way of overcoming the gap between science and practice, it is also an important tool to enhance the quality of empirical research. By engaging in complex governance systems, researchers are better able to understand their dynamics. ${ }^{86}$ By translating research findings into tests, they are able to test the validity of the conclusions. By analysing the effects of these tests in terms of the dynamics they generate, they are better able to understand the working of the complex systems analysed.

\footnotetext{
${ }^{81}$ Daniel Bodansky, The United Nations Framework Convention on Climate Change: A Commentary, 18 Yale J. Int'l Law 451 (1993).

82 Joyeeta Gupta et al., supra note 7.

${ }^{83}$ Rob Swart et al., supra note 11.

${ }^{84}$ Renata Phelps and Stewart Hase, Complexity and Action Research: Exploring the Theoretical and Methodological Connections, 10 Educ. Action Res. 507 (2002).

${ }^{85}$ Colin Eden and Chris Huxham, Action Research and the Study of Organizations, in Handbook of Organizational Studies, 526-542 (Stewart Clegg, Cynthia Hardy, and William Nord, eds., 1996).

${ }^{86}$ David Byrne, Complexity Theory and the Social Sciences: An Introduction (1998); Robert Flood, Action Research and the Management and the Systems Sciences, 11 Syst. Pract. Act. Res. 79 (1998).
} 
Action research has a long tradition and provides a variety of approaches, guided by four interwoven characteristics, namely acting, learning, researching, and collaborating. ${ }^{87}$ We briefly summarize each in turn. Firstly, all action research is engaged in action on real-life issues with those who experience those issues directly. ${ }^{88}$ It demands the integral involvement of the researchers intending to improve the governance of climate adaptation and requires the regional actors to take action. In this process of co-acting, new knowledge is created through an interactive process in which actors reflect on their actions and pay attention to the way they are learning ${ }^{89}$ — our second characteristic. Outcomes have to do with new thinking, new values, and new behaviour. ${ }^{90}$ However, this learning has to be upscaled to serve as an object of scientific analysis. Action research is only successful when it results in scientifically valid and reliable knowledge which can be generalized and used as a starting point for further research. Lastly, we mention the characteristic of intensive collaboration between researchers and regional actors. In collaborative action research, the people who take action also actively participate in the research. ${ }^{91}$ Besides solving the problems at hand and contributing to general theory, collaborative action research also aims to make change and learning a self-generating and self-maintaining process in the organization.

\section{DiscusSION AND CONCLUSION}

To summarize, the regional governance of adaptation cuts across the usual boundaries in administrative scales, policy domains, the public and private sector, the known and unknown, collective and individual responsibilities, science and policy, and the long and short term. In this paper, a conceptual framework has been developed to analyse the regional governance of adaptation and to develop and test governance arrangements that can contribute to realizing adaptation options and to increasing the adaptive capacity of society. The framework has analytical, design, normative, and methodological components.

We propose three overarching principles to guide the development and evaluation of governance arrangements for climate adaptation. Good governance of adaptation should be (a) legitimate, that is, ensure transparency, accountability, fairness, and equity; ${ }^{92}$ (b) effective, that is, address the adaptation task decisively and efficiently through the right mix of strategies and tools; and (c) resilient, that is, enabling both autonomous adaptation and constructive, long-term adaptive capacity. $^{93}$

${ }^{87}$ Catrien J. A. M. Termeer and Bregje Kessener, Revitalizing Stagnated Policy Processes, 433 J. Appl. Behav. Sci. 232 (2007).

${ }^{88}$ David Coghlan and Claus Jacobs, Kurt Lewin on Re-education. Foundations for Action Research, 41 J. Appl. Behav. Sci. 444 (2005).

${ }^{89}$ Catrien J. A. M. Termeer and Bregje Kessener, supra note 88.

${ }^{90}$ David Coghlan and Claus Jacobs, supra note 89.

${ }^{91}$ W. Whyte, ed., Participatory Action Research (1991).

${ }^{92}$ Ernest Alexander, supra note 71.

${ }^{93}$ Carl Folke, Resilience: The Emergence of a Perspective for Social-Ecological Analyses, 16 Global Envir Change 253 (2006); Joseph Arvai et al., supra note 7; Per Olsson et al., supra note 7. 
In the public domain, legitimacy is considered to be a basic condition without which the pursuit of public good is plagued by deadlock, resistance, and even collapse. ${ }^{94}$ More philosophical conceptualizations of legitimacy refer to virtues of politicians, political institutions, and, in our case, governance arrangements. Governance arrangements are legitimate when they ensure transparency, accountability, fairness, and equity, and when they are trusted by societal actors. In the Netherlands, it is generally assumed that adaptation to climate change is in the public interest. ${ }^{95}$ This is one of the basic premises on which governments act, thereby regulating land and water use at the international, European, national, and regional level. The question we have considered is whether adaptation to climate change is a new overarching public interest or whether it requires a new way to deal with existing public interests.

Effectiveness boils down to the basic question of "does it work?" A governance arrangement is effective when the chosen mixture of tools and strategies fulfils the wishes of those involved. ${ }^{96}$ The right mixture always depends on the content and context of the problem at stake. Effectiveness alone is not enough, and it therefore needs to be connected to efficiency: "The desired effect must be achieved as economically as possible, with the minimum of governmental resources and the minimum burden... on the general public" ${ }^{97}$ In our view, the good governance of adaptation requires arrangements to be not only legitimate and effective, but also resilient. ${ }^{98}$ Through this criterion, the specific challenge of dealing with long-term uncertainties and the tensions between implementing strategies and enhancing adaptive capacity is addressed. This implies that the arrangements should enable short-term interventions and autonomous adaptation and build long-term adaptive capacity without diminishing traditional legality and legitimacy. ${ }^{99}$ It requires governance arrangements to be both robust and flexible at the same time.

On the basis of the general analysis presented here, we conclude that applying existing insights from governance literature to the issue of climate adaptation only in an instrumental way is not sufficient. The specific complexities of the governance of adaptation call for the development of new and advanced governance knowledge.

\footnotetext{
${ }^{94}$ Jutta Brunnée and StephenToope, supra note 80; Lon L. Fuller, The Morality of Law (1969); Herbert Lionel Adolphus Hart, The Concept of Law (1961).

95 This will be the same in many states, but in the United States, for example, this still requires a reframing of the law to properly adapt to climate change (see Robin Kundis Craig, supra note 70) and also a regional approach: Barbara Cosens, Transboundary River Governance in the Face of Uncertainty: Resilience Theory and the Columbia River Treaty, 30 J. Land Resources and Env'l Law 229 (2010).

${ }^{96}$ Christopher Hood and Helen Margetts, The Tools of Government in the Digital Age (2007).

${ }^{97}$ Ibid, at 145.

${ }^{98}$ Carl Folke, supra note 94; Joseph Arvai et al., supra note 7; Per Olsson et al., supra note 7,

${ }^{99}$ Jonas J. Ebbesson, supra note 80.
} 